is a professor of science education at Kristianstad University. He has long experience of teaching in schools at dif-

ferent levels as well as in teacher education. His main focus of research is on the development of students' understan-

ding of ecological processes.

Sofia Helldén is an experienced teacher in grade 3-5 in the Swedish comprehensive school.

GUSTAV HELLDÉN

Kristianstad University, Sweden

gustav.hellden@hkr.se

SOFIA HELLDÉN

Önnestad School, Kristianstad, Sweden

sofia.hellden@utb.kristianstad.se

\title{
Students' early experiences of biodiversity and education for a sustainable future
}

\begin{abstract}
In order to be able to help students to read nature and to get an ability to discern both biodiversity in different contexts and changes in the environment we need to investigate how they experience biodiversity and how they discern different components in an ecosystem. Therefore, we undertook an interview-study of fifteen 10-12 year old students' experiences of biodiversity and how they discerned organisms in different ecosystems. We analysed how they described the organisms and how they referred to experiences from everyday life. After two years we interviewed the students about what they said in the initial interview. Experiences of biodiversity at an early age seemed to be important for the future development of their understanding. It is important, both to give children early experiences of biodiversity in nature and to take students' early ideas into consideration in teaching for lifelong learning and for a sustainable future.
\end{abstract}

\section{BACKGROUND, AIMS AND FRAMEWORK}

During the last decades, an increasing awareness has developed that humankind will have to make important decisions about the environment. These decisions will demand substantive knowledge of critical ecological phenomena like biodiversity.

Having spent a lot of time in nature together with students of different ages, we have experienced a great curiosity and fascination among young people about the biodiversity they experience around them. As teachers, we have also seen that there is a great variation in students' abilities to discern biodiversity in nature. With these students' experiences of biodiversity as starting points, it is a possibility to help students to develop an understanding and ability to apply concepts of biodiversity. Such a teaching strategy can be an important contribution to education for sustainable development (UNESCO, 2004).

According to the Swedish Biology curriculum, biodiversity is one of the four central dimensions characterising of the subject of biology. The other dimensions are ecosystem, cells, and human being. In the curriculum, biology diversity is presented in the following way: The subject presents the 
way in which the biological sciences organise and systematise the diversity of nature. Fundamental starting points are theories about the ecosystem and evolution, as well as knowledge of different species and knowledge of the living conditions and relations between plants and animals. Everyday experience of diversity in nature is often ethical or aesthetic and expressed, for example, in different forms of environmental involvement. One of the most important contributions biology can make to studying Man's relationship with nature is thus to show the diversity of forms of life from scientific, aesthetic and ethical perspectives (www.skolverket 20080426).

Among the goals that pupils should have attained by the end of the fifth year (12y) in school are those concerning nature and Man

- to recognise and be able to name common plants, animals and other organisms in the local environment, as well as be familiar with their environmental requirements.

- to be able to give examples of the life cycle of some plants and animals and their different growth processes.

Among the goals that pupils should have attained by the end of the ninth year (16y) in school concern nature and Man

- have a familiarity with some of the world's ecosystems and how interrelationships between organisms can be described in ecological terms.

Biodiversity on earth can change because of our influence on the natural environment. The ability to identify such changes can give us important insights into the status of an ecosystem. In order to help students to read nature and get an ability to discern biodiversity in different contexts and hopefully also discern such changes, we need to investigate how they experience biodiversity and how they discern different components of the ecosystems.

Experiences during the early years at school are important for the development of the students' understanding later in life. During a longitudinal study of students' understanding of ecological processes the first author found that early episodes in childhood in many cases seem to have an important influence on their future learning about scientific phenomena. The unique possibility offered by the longitudinal design, of letting the students read and listen to what they said on an earlier occasion, offers advantages. Thus by using such an approach the students can contribute to the interpretation of interview data since they have important information about the roots of their explanations of scientific phenomena (Helldén, 2005). Other researchers like Hutchison (1998) argue that middle childhood is a crucial period for the emergence of a child's working theory of the world. He says that it is important to meet children's ideas about nature and environment because certain values and beliefs may be rooted in this sensitive period of development.

It has been argued that it is much harder to show how educational experiences influence attitudes and behaviours and whether they will lead to a more environmentally positive behaviour, than to show that people learn a lot about creatures in different ecosystems. However, we cannot wait for education to work since biodiversity is disappearing before our eyes (Braus, 2003). It would be of greatest importance to investigate students' ability to discern the variation of organisms in different ecosystems and what kind of early experiences of biodiversity they have. If we know more about children's discernment of organisms in nature, insights are gained into teaching and curriculum design and build on children's understandings.(Shepardson, 2002). From another perspective children are a useful group to target for biodiversity education because they can be more receptive to new ideas than adults and yet influence the behaviour of adults they come into contact with (Barker \& Elliott, 2000). In order know more about children's discernment of biodiversity we carried out an interview study of how 10-12 year old students described the diversity of life. The present study was carried out from a perspective that learning involves both social interaction and individual construction of knowledge. 
The aims of the research project presented in this paper are

- to study how students discern biodiversity in different ecosystems

- to investigate the importance of previous everyday experiences for their ability to talk about the organisms

- to discuss the results from this study in relation to education for a sustainable development.

Ausubel's theory of meaningful learning (Novak,1998) was used as a framework for the analysis of the interview data and guided the description of students' conceptions. According to the theory, new ideas are integrated into the learner's thinking through a process of progressive differentiation. This process starts in childhood and continues throughout life. When new ideas are integrated into the learner's thinking, already existing conceptions can change and new meanings can be added to those conceptions. The theory explains the ways learners use current meanings and construct new meanings. According to Ausubel's theory, the following three prerequisites are necessary for meaningful learning to take place: 1.The subject matter to be learnt must be meaningful to the learner. 2. The learner must have a conception that relates to the new information to be learnt. 3. The learner must choose to learn meaningfully. The present study was also carried out from a perspective that learning involves both social interaction and individual construction of knowledge.

\section{METHODS AND SAMPLES}

In order to know more of how students experience biodiversity in different ecosystems, we interviewed fifteen 10-12 year old students individually about what organisms they saw on four different occasions: 1 . Plants in a meadow surrounded by trees and bushes in early June 2. Water organisms in a sample from a pond in September. 3. Plants on the slopes along a stream in early October. 4. Soil invertebrates in a sample of litter with decaying material from a deciduous forest in November. During the interviews the students were also asked to describe how they recognised the organisms.

We also took notes and audio-recorded some students' discussions during bird watching in a wetland in May. All the students in this study belonged to the same class of a primary comprehensive school that is situated in the countryside near a small town in southern Sweden. The class was an integrated class with students belonging to grade $3(10 \mathrm{y}), 4(11 \mathrm{y})$ and $5(12 \mathrm{y})$. The students have had a monthly nature walk since they were six years of age. All of the interviews were audio-taped and transcribed verbatim.

During the analysis of the interviews we found interesting features in the students' descriptions of organisms and ecosystems. Experiences from a previous longitudinal study of students' understanding of ecological phenomena have shown that students can contribute to the interpretation of previous interviews with them (Helldén, 2005). In order to be able to carry out a more complete analysis of the interviews, we interviewed students again in the present research project 2 years after the first interview occasion. After they had listened to their initial interviews we asked them to comment on what they had said 2 years before and why they said as they did.

\section{FINDINGS}

We analysed the transcripts of the interviews with the 15 students concerning their ability to discern plants or animals in the four cases. We also investigated how they described the organisms and to what extent they referred to experiences from everyday life when they talked about the plants and animals.

A group of seven students had a good ability to discern organisms on the four occasions. They did not always know the names of some organisms but could often give detailed and sometimes 
colourful descriptions and characteristic features of what they saw. When they described the plants in a meadow in the first interview, they commented on what the plants looked like and about the plants' role in everyday life.

Students in this group were also able to make comments on the characteristics of the invertebrates in the litter and freshwater sample. All the interviewed students were less familiar with the organisms in the freshwater sample but some students in this group of seven students referred to terrestrial organisms when we asked them to describe what they saw in the sample with water invertebrates.

These students often linked their descriptions spontaneously to what they had experienced in everyday life as in the following comment to the organisms in the water sample: "But I do not know but I think they are mosquito larvae. We found such creatures in a bucket at home. They appear when it has been raining." Episodes they have experienced together with family members seem to be of great importance for the students' ability to identify the plants and animals. This was also the case when I asked them why they could identify the plants and animals. When Betty found a beechnut in the litter sample, she reminded herself about an event together with her grandma: "I do not know what it (beechnut) is called, but I think you can open it and eat what is inside of it. This is what I did with my grandma who lives in the forest." The students in this group more often expressed feelings of admiration or annoyance than students in the following group of eight students when they talked about different organisms.

Kajsa is a girl who loves to be out in nature and find new interesting things. She said that the most important thing was to see the many different organisms, not always to know the names.

When she had identified a wood-lice in the litter from the woods, she said: "They are among the leaves behind grandpa's garage. There are planks. We lifted them up and there came spiders and such animals creeping." She had a rich language when she described the organism. Kajsa seemed to be fascinated to recognise the different life forms. Here follows a part of the interview with her about what she saw on the bank along a stream. (I= Interviewer; $\mathrm{S}=$ Student)

I: If you look at this bank from the fence and let your eye sweep over the vegetation, how would you describe the vegetation?

S: A lot of green and many different plants and flowers, cob web and a dried up brook.

I: If you just look at the plants. What do you see in front of you? Perhaps you don't know the names, but ....

S: Daisies.

I: How do you recognise them?

S: They (The flowers) are yellow in the middle and have narrow white leaves.

I: That was the daisy and...

S: There is a dandelion.

I: Why do you see the dandelion at once?

S: They are so yellow. The colour catches your eye, when you check everything that is green, you see the yellow flowers. I don't know the name of that red flower that easily drops its leaves.

I: How can you identify this dock?

S: The leaves look like a rabbit's ears. And there are plants that look like a hare's foot.

At the end of the interview Kajsa told us that she had learnt a lot about plants in school but also at home when she had helped weed in the garden. She offered colourful and quite detailed descriptions of the organisms. Therefore, it was with great interest we interviewed her two years later at 14 years of age after she had listened to the previous interview with her about plants in the meadow and about organisms in the litter from the woods. She said that she also was interested in grasses and that she had learnt about plants all the time not only in school but also together with others 
in leisure hours, for example when they picked flowers for the maypole. Here follows a transcript from a part of an interview, after she had listened to the previous interview about the litter from the woods. (I=Interviewer; $\mathrm{S}=$ Student)

I: What do think about you descriptions two years ago?

S: I was often outdoors together with my brother when we were children. At home we had a garden plot where we could find snails and worms. On the back yard of our grandpa's house we found planks with woodlice. When you lifted these planks a lot of bugs came forward.

I: But there must have been somebody telling you that it was a woodlouse. Do you remember when you learnt about woodlice?

S: When I consider, I think I was 6-7 years of age and perhaps I learnt it at school. About spiders, they are not dangerous but they look unpleasant. You see beetles often when you are at field trips, when you sit down to have something to eat and drink. You learn a lot when you are out there in nature.

I: When do you think you learn best?

$\mathrm{S}$ : It is more fun to experience something out in the woods, not only read about things in a book. The more you are outdoors the more you can find bugs. You don't know what to find.

One student in this group, Albin distinguished himself by discerning many life-forms in the four cases. When he was asked to pick different plants in a meadow during the first interview, he noted many individual species, even though he did not know the name. He willingly used colours and other characteristic details in his descriptions. When he described plants in a meadow, he made comments about what the plants looked like and their role in everyday life of people. He was the only student who spontaneously identified correctly the trees and bushes in the background during the meadow interview: "I think it is a chestnut tree, a birch tree, a maple tree and some kind of hazel." When Albin had told the interviewer what flowers he saw on the banks along the stream, he was asked how he thought he had learnt to recognise the organisms. He talked about seeing them many times and reading about them in books. Albin was also able to make comments on the characteristics of the invertebrates in the litter and in the freshwater sample. No other student in the group showed such ability.

When Albin listened to his initial interview from 2 years previously, concerning his description of grasses in the meadow, he referred to a game that is common among Swedish children: "You pull the panicle upwards with your fingers to see if it will be cock, hen or chicken." When the interviewer asked him why he could identify so many trees and bushes during the meadow interview, he said: "At that time I was more interested to read about such things. Or I was walking in the forest and dad told me what kind of trees there were."

Albin thought that he knew more about plants and animals in his earlier interview, as evidenced by the following transcript about organisms in the litter from a deciduous forest.

( $\mathrm{I}=$ interviewer $\mathrm{S}=$ student)

I: What do you think, when you have listened to what you said two years ago?

S: I probably knew more about insects and sort of than I know today, what I remember.

I: You could identify leaves from chestnut and oak tree. When did you learn such things?

S: It was when we were outdoors together with Birgitta (a teacher) and walked to the chestnut tree here in the near neighbourhood.

I: Do you remember when you learnt to recognise these organisms as a child?

S: Yes, those woodlice... there was a minor forest with a lot of stones. We used to lift them and there were a lot of such woodlice there. And there were beetles too. 
I: At what age did you start to recognise animals?

S: I think I was five.

I: And it was fun to be there in the woods?

$\mathrm{S}$ : Yes but it was frightening too.

I: Lars, how do think you learn to identify plants and animals?

S: When I see them often, I try to remember them. I observe them several times and ok that one I remember.

I: Do you learn the name of plants and animals?

$\mathrm{S}$ : Yes, some of them are quite easy to remember. Some names sound strange and different. Perhaps you remember them more easily.

Another group of eight students had only a weak ability to discern organisms in the four cases. Even if some of the students discerned organisms, they did not talk about characteristic features of the plants and animals. Unlike the previous group of students, their descriptions did not contain such detailed and colourful features. In some cases also these students referred to terrestrial organisms when they talked about organisms in the freshwater sample. They quite seldom referred to personal everyday life experiences when they talked about organisms. This group of students used of few words when they talked about what they saw in nature or in the samples.

Here follows a segment from the interview with Greta at 14 years of age after she has listened to her previous interview about plants in the meadow and about organisms in the litter from the woods.

I: You recognised some plants in the meadow, a maple and a birch tree. Why did you recognise them?

S: I think I have seen them before, and somebody has told me about them. I was often standing near a maple tree outside the school, and I saw how the tree changed.

I: You recognised the birch tree!

S: Yes, we have a birch tree at home.

I: How did you recognise the dandelion?

S: It is yellow and has strange leaves.

I: How did you find out that?

S: I have learnt it in some way.

I: When do you think you learn about such a flower?

S: You learn this when you are a little child, I think.

I: Why do you say like this about this from the woods?

S: I don't know. I have got to know it somewhere.

I: You had the leaves here and identified a woodlouse, a beetle, a caterpillar, and a spider. How could you?

S: From the preschool years. We were out in the woods with Linda (teacher) in grade 0-2.

I: Is it something you have seen at home?

S: Yes, spiders, we have lot of them at home. I don't like them. They are creeping everywhere.

I: Wood lice, you recognise them, don't you.

$\mathrm{S}$ : Yes, we used to have them under the seats and beside the big stairs.

I: Do you remember something especially fun?

S:

In considering their initial interviews students referred to concrete pleasurable early experiences they had had together with family members in a garden or in the woods. They emphasised several times the importance of the short walks in nature their class had taken together with their teacher Birgitta in early primary. During such events, the students were able to identify and talk about some key organisms that they could later refer back to when they saw organisms in nature. 


\section{Discussion}

There are severe changes of the biodiversity on earth. The changes are not that easy to identify, because they come by small steps. We argue that it is important to give students a preparedness to discern changes in the natural environment in the future. We also need to develop their ability to discern biodiversity. Therefore this is an important part of education for a sustainable future (UNESCO, 2004).

To discern the diversity of life forms is an important to the ability to read nature. The ability to read nature can be seen as an aspect of ecological literacy. Its focus is on ecology and the context is outdoors. The concept of ecological literacy has not only to do with recognition of organisms but also an ability to relate the organisms to material cycling and energy flow in a habitat (Magntorn \& Helldén, 2007).

Clearly from the investigations reported here, there are great differences in students' ability to define organisms and to discern characteristic identifying features organisms. For example we found that concrete experiences of biodiversity both in school and in everyday life play an important role in the development of a student's ability to discern biodiversity. This was obvious when the 14 year old students listened to their initial interviews.

Students who were more successful in discerning plants and animals in nature and in samples from a pond or forest, referred to a greater extent to everyday experiences often with feelings of joy and curiosity with all senses involved. However, these students also referred to concrete episodes at school that had been important for the development of their ability to identify organisms. For example, in grade 0-2 (6-8) One teacher carried out nature walks in the near neighbourhood of the school to follow seasonal changes. Some students felt as 14 year olds that they knew more about different kinds of organisms when they were younger because of these episodes. Even the students with less developed ability to discern organisms in the different habitats said they had learnt to identify organisms as a result of the nature walks. Such episodic memory plays an important role in the development of students' understanding (Helldén \& Solomon, 2004).

Experiences in the early years can be an important part of the personal context that characterises the development of students' ways of explaining biological phenomena. Long-term studies have shown that early experiences in childhood have an important impact on the development of the students' future learning about processes in nature (Helldén, 2005).

We agree with Chawla (1998) that particular early experiences seem to influence a person's future environmental sensitivity. That means that it is important to create experiences early at school that stimulate the students' interests and challenge them to explore natural phenomena. The investigations in the present research project have shown that lots of experiences from the early years have influenced students' ways of talking about organisms in nature. But we think it is also important to meet children's ideas about nature and environment in the middle childhood, especially as research has shown that this period of the students' development is fundamental to the child's working theory of the world (Hutchinson, 1998).

The students' descriptions of their own learning can be described as a process of progressive differentiation. The students had subsumed new concepts and experiences of organisms to their present thinking. Through such a process of ongoing subsumption the students can develop their ability to discern biodiversity by attaching the identity of newly-encountered processes to those they already know. In order to facilitate such meaningful learning it is important that teaching builds upon what the learner already knows (Novak, 1998).

Symons (2001) claims that there is a long tradition in Britain of teaching and learning about the natural environment in primary schools where primary teachers build upon the enthusiasm and 
curiosity young children have for organisms in nature. The children are in this way introduced to positive and hopeful aspects of life. In our studies we have experienced the same fascination not only at primary but also at secondary level.

The present study has shown that early experiences of identification of some key plants and animals are important, especially if such experiences are connected to episodes in everyday life. Pleasure and joy as well as pride in being able to identify organisms are important parts of such experiences. Not only thinking ,but also feeling and acting are important components in education (Novak, 1998).

The overall aims of the subject of biology are formulated in the following way in the first part of the Swedish Biology curriculum. This could also have reference to biodiversity education as a part of education for a sustainable future.

The subject of Biology aims at describing and explaining nature and living organisms from a scientific perspective. At the same time the education should consolidate the fascination and joy of discovery and Man's wonder and curiosity in all that is living. The subject also aims at making knowledge and experiences usable to promote concern and respect for nature and one's fellow men. (www.skolverket 20080426)

\section{REFLECTIONS AND CONCLUSIONS}

The students participating in this study showed great interest to investigate the richness of organisms the four contexts. In the group of students with a good ability to recognise and describe plants and animals, they often refer to episodes they have experienced in everyday life. Experiences together with family members seem to be of great importance for their ability to identify the organisms. These students often refer to experiences in early childhood and during the first years at school. They also give more detailed and colourful descriptions of the organisms than in another group of students with less ability to discern biodiversity and describe the organisms. This second group of students does not refer to everyday experiences in the same extent as the first group. Students in this class stated in the interviews that the monthly nature walks together with a teacher in the early years at school have been important for their learning about plants in nature.

As a result of the present study we argue that students' early experiences of organisms in different habitats are of great importance for the development of their ability to discern biodiversity.

Therefore, in order to help students to develop a good ability to discern biodiversity we need

- to give children early experiences of biodiversity in different habitats with joy and all senses involved

- to give them opportunities to talk about their experiences of different creatures in nature

- to use students' previous experiences of biodiversity as a point of departure for teaching.

This study has also shown that you can get interesting information about student learning by interviewing the 14 year old students after they have listened to the initial interviews with them. They can unveil interesting details concerning their previous descriptions of the organisms. The 14 year old students can also give information about important experiences that might influence their answers during the interview two years before.

In Sweden we have a deeply rooted tradition in primary education to introduce students to studies in nature. During regular excursions to different biotopes the students can follow the development of the environment through the seasons of the year. These excursions are important events where the students can have experiences that can play an important role in the future development of their understanding of and attitude to the environment. During such events the students have possibilities to develop their ability to recognise and name organisms in the local environment and 
become familiar with life cycles and growth processes as it is formulated in the Swedish Biology Curriculum. What students experience and learn during fieldwork contributes to the development of their awareness of the diversity of different life forms, an awareness of biodiversity.

We have experienced how many students express joy and fascination for example during investigations of the diversity of plants and animals in a meadow or during an excursion with bird watching in wetlands. They can also express pride in describing what they have found and perhaps being able to identify things by name. Hopefully such experiences can help students to develop their ability to 'read nature' and discern the role of some key organisms in ecosystems in their near neighbourhood (Magntorn, 2007). This can be of great importance for their future view of biodiversity and a part of their learning for a sustainable future. Such experiences can give the students a preparedness to act when biodiversity is hit by serious changes in the future.

We assume that this is what Jerome Bruner (1996) referred to, when he argued that the first object of learning, above and beyond the pleasure it may give, is that it should serve us in the future. Such a strategy might also characterise education for a sustainable future by helping students to discern changes in biodiversity in nature.

\section{AKNOWLEDGEMENT}

We wish to thank Professor Georges Dussart, Christ Church College Canterbury for valuable comments on an earlier version of this paper.

\section{REFERENCES}

Barker, S. \& Elliott, P. (2000) Planning a skills-based resource for biodiversity education. Journal of Biological Education 34 (3) 125-127.

Braus, J. (2003) Learning about learning. In Scott, W. \& Gough, S. (EDS) Sustainable Development and Learning, Framing the issue. London: Routledge Falmer.

Bruner, J. (1996) The process of education. Cambridge: Harvard University Press

Chawla, L. (1998) Significant life experiences revisited: A review of research on sources of environmental sensitivity. Journal of environmental Education, 29(3), 11-21.

Helldén, G.F. \& Solomon, J. (2004) The persistence of personal and social themes in context: Long and short term studies of students' scientific ideas. Science Education 88, 885-900

Helldén, G. (2005) Exploring understandings and responses to science: A program of longitudinal studies. Research in Science Education 35, 99-122.

Hutchinson, D. (1998) Growing up green: Education for ecological renewal. New york: Teacher college Press.

Magntorn, O. (2007) Reading nature. Developing ecological literacy through teaching. (Studies in Science and Technology Education. No6) Doctoral Thesis. Linköping University: Educational Sciences.

Magntorn, O. \& Helldén, G. (2007) Reading new environments: Students' ability to generalize their understanding between different ecosystems. International Journal of Science Education 29 (1), 67-100.

Novak, J. D. (1998) Learning, creating, and using knowledge: Concept maps as facilitative tools in schools and corporations. Mahwah, NJ: Lawrence Erlbaum Associates.

Raus, J. (2003) Learning about learning. In Scott, W. \& Gough S. (EDS) Sustainable Development and Learning, Framing the issue. Routledge Falmer: London

Shepardson, D. P. (2002) Bugs, butterflies and spiders: children's understanding about insects. International Journal of Science Education 24 (6), 627-643.

Skolverket (National Agency for Education). www.skolverket.se

UNESCO (2004) Educating for a sustainable future: Commitments and Partnerships. Proceedings of high- level international conference on education for sustainable development at the world summit on sustainable development in Johannesburg 23 September 2002. 